\title{
Modification of Roll Flattening Analytical Model Based on the Plane Assumption
}

\author{
Tao Wang ${ }^{1}$, Qing-Xue Huang ${ }^{1 *}$, Hong Xiao ${ }^{2}$ and Xiang-Dong Qi ${ }^{2}$
}

\begin{abstract}
Roll flattening is an important component in the roll stack elastic deformation, which has important influence on controlling of the strip crown and flatness. Foppl formula and semi-infinite body model are the most popular analytical models in the roll flattening calculation. However, the roll flattening calculated by traditional flattening models has a great deviation from actual situation, especially near the barrel edges. Therefore, in order to improve the accuracy of roll flattening, a new model is proposed based on the elastic half plane theory. The calculation formulas of roll flattening are deduced respectively under the assumptions of plane strain and plane stress. Then, the two assumptions are combined through the method of introducing an transition coefficient, and the distribution rules of roll flattening for different rolling force, flattening width, roll length and roll diameter are analyzed by using the FEM analysis software Marc. Regarding the ratio of the length to roll end and the roll diameter as variable to fit the transition coefficient, the new model of roll flattening is established based on the elastic half plane theory. Finally, the transition coefficient is fitted to establish the model. Compared with the traditional models, the new model can effectively improve the calculation deviation in the roll end, which has important significance for accurate simulation of plate shape, especially for the distribution of rolling force between rolls.
\end{abstract}

Keywords: Roll flattening, Plane strain, Plane stress, Transition coefficient, FEM

\section{Introduction}

The flattening between work roll and strip and the flattening between rolls are important components of the important influence on controlling of the strip crown and flatness [1-10]. For the flattening between work roll and strip, because of the strip width is shorter than the work roll length more the $200 \mathrm{~mm}$ and the contact arc length is far less than roll diameter, the work roll can be seen as semi-infinite body and it's reasonable to use the elastic half space theory $[11,12]$ for roll flattening. For the flattening between rolls, because of the length of back up roll is almost equal to the work roll (or the back-up roll length is less than the work roll), using the semi-infinite body assumption is obviously unreasonable, especially for the shorter one, and the Foppl formula [13] is employed for solving this frequently. The space problem is simplified

\footnotetext{
*Correspondence: hqx@tyut.edu.cn

${ }^{1}$ College of Mechanical Engineering, Taiyuan University of Technology, Taiyuan 030024, China

Full list of author information is available at the end of the article
}

into plane problem in Foppl formula, which ignore the influence of the axial stress, so the deviation in the roll end still exists. Figure 1 shows the comparison between the actual situation and the results calculated by the two models under the condition of uniform load.

Many scholars have studied on this problem, Berger et al. [14] established a way for the roll flattening calculation considering the pressure gradients along the roll axis direction. Based on Berger's theory, Hacquin et al. [15] proposed a semi-analytical model by coupling with the analytical model and FEM. Yu et al. [16-18] chosen Foppl formula as the roll flattening model and established a roll deformation model of 20-high mill. Coupled with the metal plastic deformation, the effects of work roll crown and the second intermediate non-drive roll crown on strip edge drop were analyzed. Jiang et al. $[19,20]$ chosen the semi-infinite body as the roll flattening model and proposed a roll deformation model in cold thin strip rolling with roll edge contact. Then, the mechanics of the cold strip rolling was analyzed based on the model. Zhou et al. [21, 22] examined the validity 


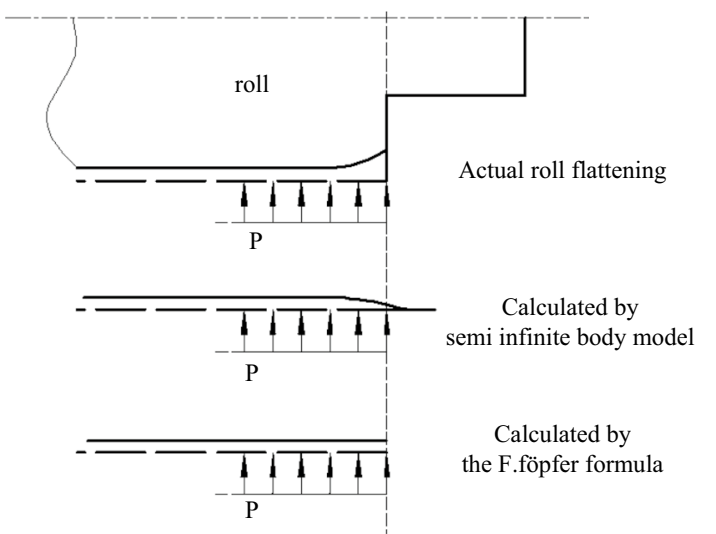

Figure 1 Sketch map of flattening calculation models

of the classical formulae by comparison of the results from different methods and modified the semi-infinite body model based on FEM. Xiao and Yuan et al. [23-27] analyzed the error of semi-infinite body model in roll calculation and proposed an analytical model in flat rolling by boundary integral equation method. Wang et al. [28] used the 3-D elastic-plastic FEM to simulate the thin strip rolling process of UCM cold rolling mill. In the model, a novel calculation approach is proposed to obtain the actuator efficiency factors of the flatness actuators in terms of intermediate roll bending, work roll bending and intermediate roll shifting. Du and Linghu et al. [29-31] developed a 3-D FEM simulation model of six-high CVC rolling process by using nonlinear elasticplastic finite element method and the elastic flattening of rolls and the elastic workpiece are coupled as a whole in the model.

From the existing research results, it's seen that the analytical method based on semi-infinite body model lack of theoretical support and the FEM cost considerable time [32]. For the geometry and stress situation of the work roll and back-up roll, the space problem can be simplified to plane problem approximately, which can effectively reduce the amount of calculation and meet the engineering precision requirement. In this paper, the roll flattening model is analyzed and modified based on the elastic half plane theory.

\section{Formula Derivation Based on Elastic Half Plane Theory}

For the rolls, whose cross section shape is circular, and its boundary bears the pressure $p$, which is balanced with shear stress. The sketch map of force analysis is shown as Figure 2.

Assuming the distribution of pressure $p$ along the direction of flattening width $2 b$ is elliptical and according

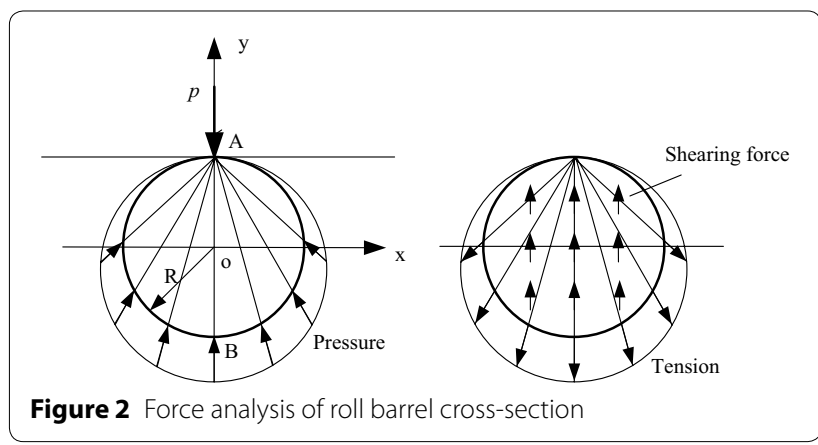

to the elastic theory [33], the stress component of the roll cross section along the directions of the $X$ axis and $Y$ axis in the rectangular coordinate system can be expressed as:

$$
\left\{\begin{array}{r}
\sigma_{x}=p_{0}\left[\frac{b(R+y)}{4 R^{2}}+\frac{b}{\sqrt{b^{2}+(R-y)^{2}}}\right] \\
\left.-2 \frac{\sqrt{b^{2}+(R-y)^{2}}-(R-y)}{b}\right], \\
\sigma_{y}=p_{0}\left[\frac{b(R-y)}{4 R^{2}}-\frac{b}{\sqrt{b^{2}+(R-y)^{2}}}\right] .
\end{array}\right.
$$

For the roll flattening, the change from the roll central to the edge can be regarded as a transformation which is from plane strain problem to plane stress problem, that is say, when the roll bears uniform load, the minimum size of flattening occurs in the middle, which is suitable for the plane strain assumption, and the maximum size of flattening occurs in the edge, which is suitable for the plane stress assumption. So, the calculation formulas are deduced under the two assumptions.

(1) Plane stress assumption (the axial stress is 0 )

According to the Hooke's law, the equation can be obtained as follows:

$$
\varepsilon_{y}=\frac{1}{E}\left(\sigma_{y}-v \sigma_{x}\right)
$$

The axis deformation along $Y$ axis can be obtained by integration:

$$
\delta=-\int \varepsilon_{y} \mathrm{~d} y=-\frac{1}{E} \int\left(\sigma_{y}-v \sigma_{x}\right) \mathrm{d} y .
$$

The flattening deformation in bearing area $O A$ can be obtained by Integration from 0 to $R$ : 


$$
\Delta R=\frac{2 p}{\pi E}\left[\ln \frac{2 R}{b}+\frac{1}{8}(3 v-1)\right] .
$$

The flattening deformation in nonbearing area $O B$ can be obtained by integration from $-R$ to 0 :

$$
\Delta R^{\prime}=\frac{2 p}{\pi E}\left[\ln 2+\frac{1}{8}(v-3)\right] .
$$

(2) Plane strain assumption (the axial strain is 0 )

For plane strain assumption, according to the elastic mechanics theory, the calculation formula can be obtained by replacing $E$ to $\frac{E}{1-v^{2}}$ and replacing $v$ to $\frac{v}{1-v}$.

The flattening deformation in bearing area $O A$ can be expressed as:

$$
\Delta R=\frac{2 p\left(1-v^{2}\right)}{\pi E}\left(\ln \frac{2 R}{b}+\frac{1}{8} \frac{4 v-1}{1-v}\right) .
$$

The flattening deformation in nonbearing area $O B$ can be expressed as:

$$
\Delta R^{\prime}=\frac{2 p\left(1-v^{2}\right)}{\pi E}\left(\ln 2+\frac{1}{8} \frac{4 v-3}{1-v}\right) .
$$

The sketch map of rolls under force is shown as Figure 3 , for the back-up roll, which only bears the pressure on one side and depend on the braced force in roll neck to keep balance, therefore, the roll flattening only need be calculated by the formula of $O A$ section. For the work roll, which bears the pressure on both sides, therefore, the roll flattening need be calculated not only in the bearing area (OA section) caused by the pressure between rolls $p$, but also in the nonbearing area $(O B$ section) caused by the rolling force $q$. The total size of the flattening should be the sum of the work roll' $s$ and back-up roll's.

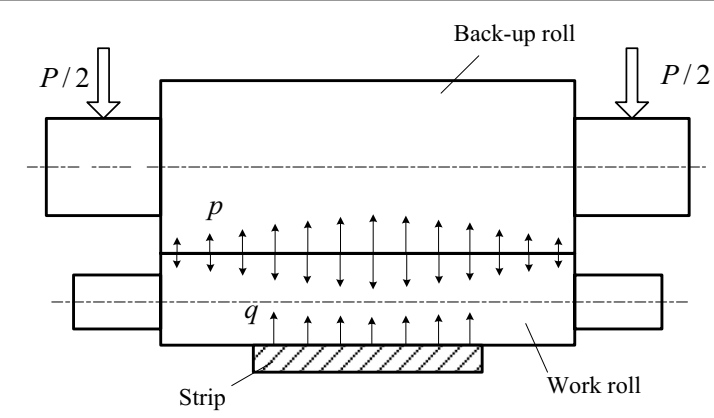

Figure 3 Sketch map of rolls under force

\section{Modification of Roll Flattening Model}

\subsection{Finite Element Simulation of Roll Flattening}

In the roll flattening calculation, because the area of plane strain assumption and plane stress assumption is uncertain, the commercial finite element software MSC. Marc is employed to simulate the roll flattening and offer reference for the comprehensive application of the two assumptions. An example is illustrated for this, in which the roll diameter is $850 \mathrm{~mm}$, the roll length is $1780 \mathrm{~mm}$ and the roll surface bears the uniform load $10 \mathrm{~N} / \mathrm{mm}$ along the direction of roll length. In order to have higher comparability between the results calculated by finite element method and plane, the flattening width is calculated by Hertz formula firstly, and then according to the elliptic curve assumption of distribution rule, the grids in stress area are subdivided to make the finite element model and analytical model have same input conditions.

Figure 4 shows the result of FEM calculation, it can be seen that the size of flattening increases gradually from the roll centre to the roll edge, because there is no constraint of normal stress and shear stress in the roll end.

In the same parameter conditions with finite element simulation, the present paper uses the plane strain assumption and plane stress assumption to calculate respectively, and gets the size of flattening in the roll central and roll end. The specific value as Table 1 shows. We can see the analytic calculation results and finite element calculation results are better matched, there are two reasons lead to deviations: the one reason appeared in the process of analytic calculation to solve integral, simplifying some expressions and ignoring some infinitesimal; the another reason is that the input conditions of two kinds of calculation methods can't reach consistent exactly, such as the distribution of roll force, and make elliptic curve equivalent with some discrete values when doing the finite element simulation.

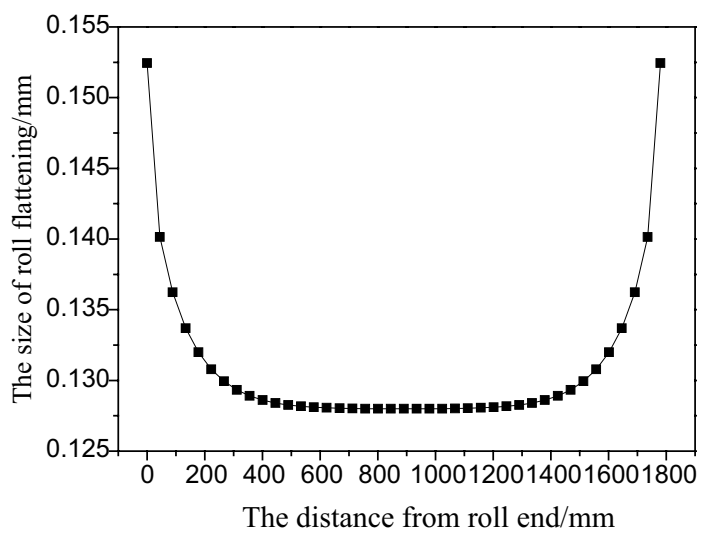

Figure 4 FEM calculation result of roll flattening 
Table 1 Comparison of roll flattening

\begin{tabular}{lll}
\hline Flattening size & $\begin{array}{l}\text { The centre } \\
\text { (minimum) }(\mathbf{m m})\end{array}$ & $\begin{array}{l}\text { The end } \\
\text { (maximum) } \\
\text { (mm) }\end{array}$ \\
\hline $\begin{array}{l}\text { Based on plane assumption } \\
\text { Calculated by FEM }\end{array}$ & 0.129 & 0.146 \\
\hline
\end{tabular}

\subsection{Introduction and Fitting Method of Transition} Coefficient

According to the result calculated by FEM, the flattening area can be divided into the central part and the edge part, as shown in Figure 5.

It can be seen that the size of roll flattening in the central area is almost the same, and it can be regarded as suiting for the plane strain assumption. The size of roll flattening increases with closing to the roll ends gradually. In order to describe the changing rule of roll flattening in edge area, the transition coefficient is introduced to express the assumption of plane stress and plane strain under external force. So, the roll flattening in arbitrary position can be calculated by the following formula.

$$
\left\{\begin{array}{lc}
\delta=\delta_{0}, & x>s, \\
\delta=k(x) \delta_{1}+[1-k(x)] \delta_{0}, & 0 \leq x \leq s,
\end{array}\right.
$$

where $\delta$ is the size of roll flattening; $\delta_{0}$ is the size of roll flattening calculated by the plane strain assumption; $\delta_{1}$ is the size of roll flattening calculated by the plane stress assumption; $x$ is the distance from the roll end; $s$ is the length of roll edge area; and $k(x)$ is the transition coefficient.

For different pressure sizes, flattening widths, roll lengths and roll diameters, the changing rule of transition coefficient is different. So, four groups of roll flattening are simulated by FEM under the conditions which are shown is Table 2.

According to the FEM results, the changing curves of transition coefficient are described as Figure 6. From Figure 6(a), Figure 6(b) and Figure 6(c) it can be seen that the changing curves are basically coincident under the conditions of different rolling forces, flattening

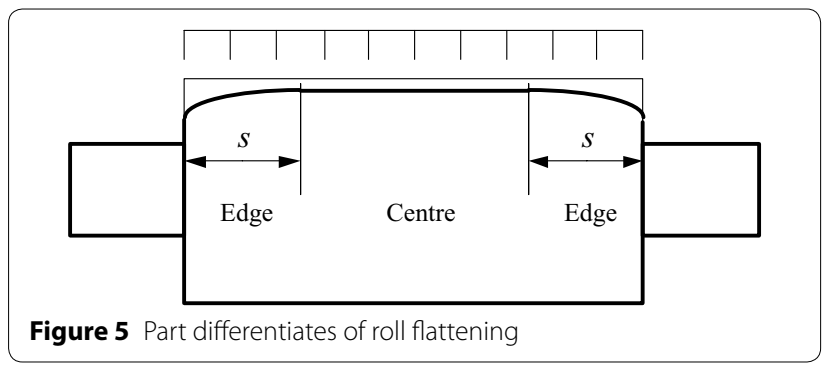

Table 2 FEM simulation conditions of roll flattening

\begin{tabular}{lll}
\hline No. & Type & Value \\
\hline 1 & Pressure size $(\mathrm{kN} / \mathrm{mm})$ & $5 / 10 / 15$ \\
2 & Flattening width $(\mathrm{mm})$ & $4 / 5.47 / 7$ \\
3 & Roll length $(\mathrm{mm})$ & $1335 / 1780 / 2225$ \\
4 & Roll diameter $(\mathrm{mm})$ & $700 / 850 / 1000$ \\
\hline
\end{tabular}

widths and roll lengths, that is to say, these three factors have little influence on the transition coefficient in a certain range, which can be neglected. From Figure 6(d) it can be seen that the roll diameter has obvious influence on the transition coefficient, with the roll diameter becoming much smaller, the transition coefficient will be close to 0 fast.

According to elastic mechanics theory, if the length of a roll which can be seen as a semi infinite body exceeds a certain value, the flattening in roll edge should be consistent under the same load, so the roll length has little influence on transition coefficient changing trend. Because roll flattening is the relative difference between roll surface subsidence and roll central, the different roll diameters will lead to different standards for roll flattening calculation. In order to analyze the roll flattening changing rule with different roll diameters, the curve of transition coefficient is drawn by taking the ratio of the distance from roll end $x$ and the roll diameter $D$ as variables, as shown in Figure 7 .

From Figure 7 it can be seen that the three curves are basically coincident. According to the variation characteristics, the index curve is employed to fit the transition coefficient $k(x)$ by taking $x / D$ as variable, which can be expressed as

$$
k(x)=a^{\left(\frac{x}{D}\right)},
$$

where $a$ is the fitting coefficient, $a=4.8269 \times 10^{-5}$.

Bring Eq. (9) into Eq. (8), the roll fattening distribution can be obtained. Figure 8 shows the comparison of calculation results between the modified model and FEM. It can be seen that the two results are basically approached, that is to say, the modified model effectively avoids the error in roll edge calculation.

\section{Influence Analysis of Roll Flattening Model on Strip Shape Simulation}

In roll stack deformation calculation, the modified flattening model can be used to calculate the flattening between rolls. Because the length of work roll is longer than strip width, it is reasonable to regard the work roll as a semi infinite body. To study the influence on strip shape calculated by different flattening models, an 

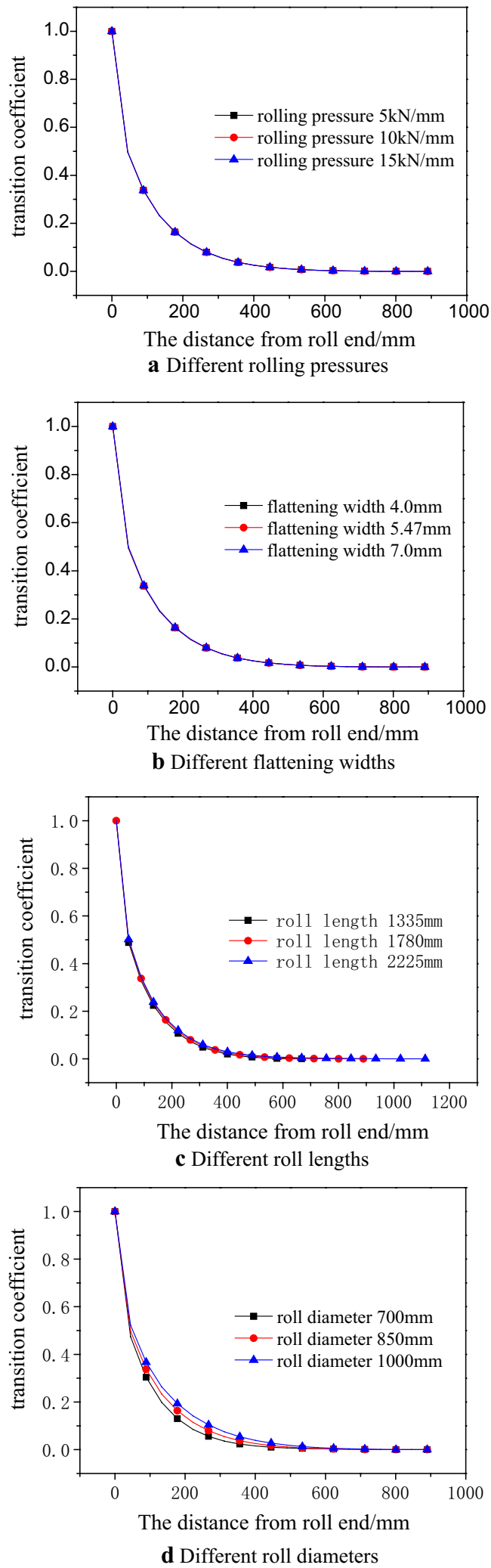

Figure 6 Changing law comparison of transition coefficients under different conditions

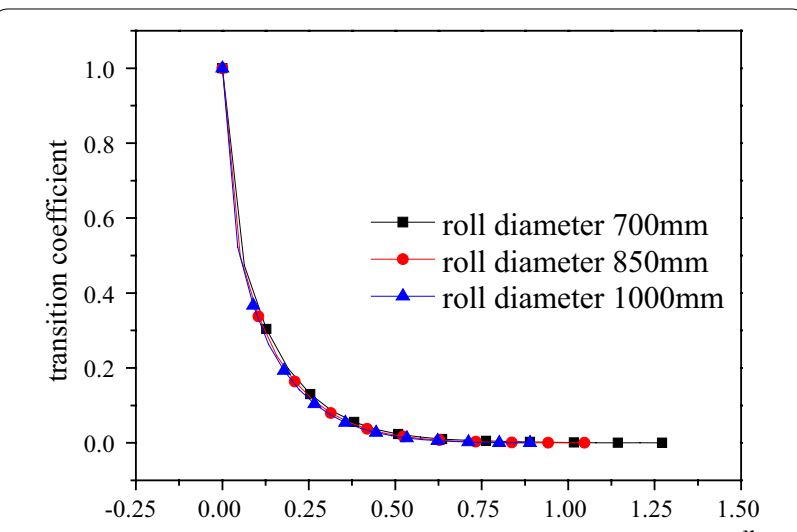

The ratio of the distanc from roll end and roll diameter $\left(\frac{x}{D}\right)$

Figure 7 Effect of different roll diameters on transition coefficient

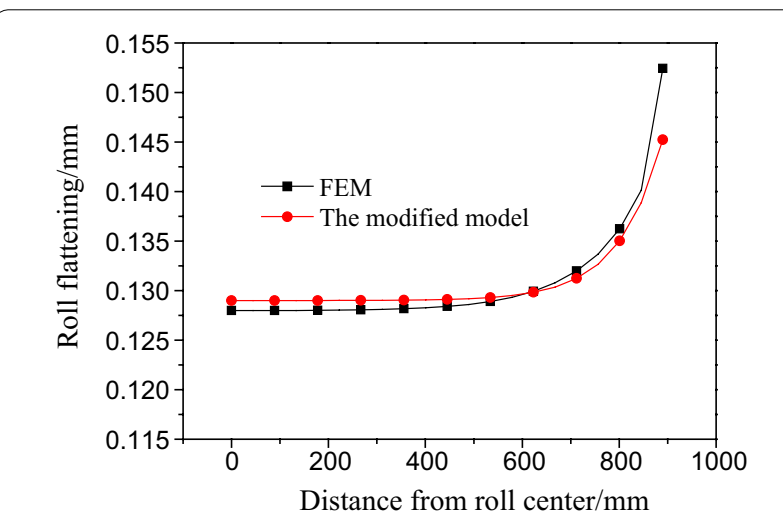

Figure 8 Calculation result comparison of FEM and modified model on roll flattening

example of F1 stand is simulated by 3-D FEM Coupled Model [34].

In the simulation of strip shape, variational method is employed to solve the lateral flow of metal and influential function method is employed to calculate roll deflection, the lateral distribution of roll flattening, pressure between rolls, strip thickness and front tension can be obtained by iterative strategy. Figure 9 shows the results.

From Figure 9(a) it can be seen that the size of roll flattening calculated by the modified model is larger than Foppl formula in the area of both ends which is suitable for plane stress assumption. As shown by the value, the extends range is about $10 \mu \mathrm{m}$ which is about $4 \%$ of the average size of flattening, while the values in roll central are basically identical. From Figure 9(b) it can be seen that the pressure between rolls in the area of both ends becomes smaller since the flattening changing. As shown by the value, the reduction range is about $1 \mathrm{kN} /$ $\mathrm{mm}$ which is more than $10 \%$ of the average pressure 


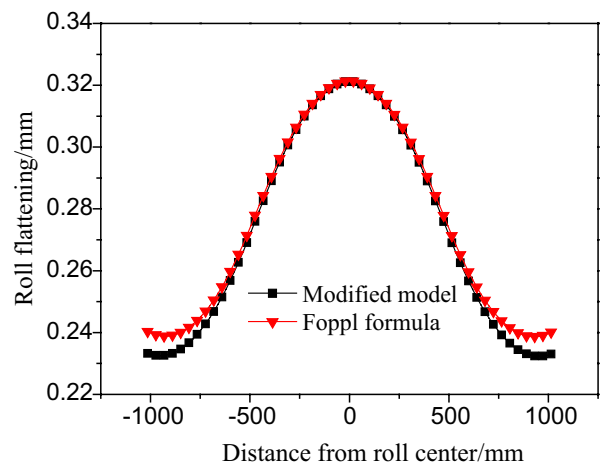

a Comparison of roll flattening

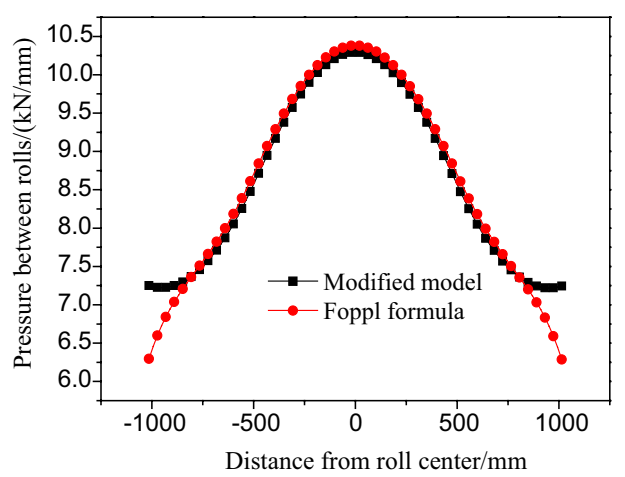

b Comparison of pressure between rolls
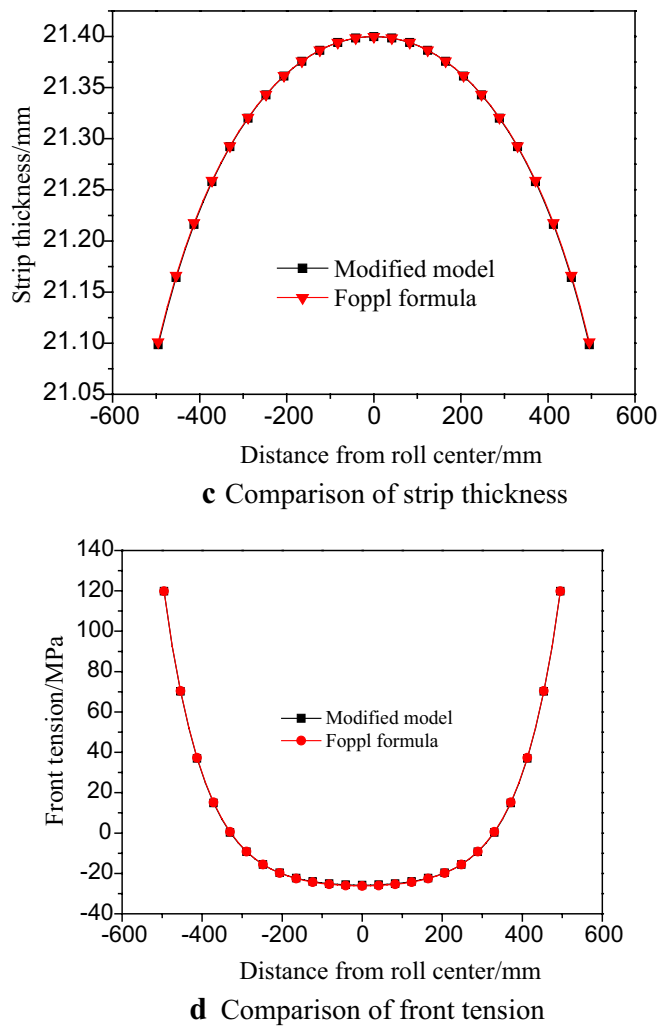

Figure 9 Effect of roll flattening models on calculation results between rolls. From the Figure 9(c) and Figure 9(d) it can be seen that the strip thickness and front tension are basically identical. Although the modification of flattening model does not have obvious influence on the final results of strip shape, the influence of pressure between rolls should not be ignored. In view of the actual production, the excessive wear of back-up rolls often appears, so the modified flattening model is of important significance for the accurate calculation of pressure between rolls in the roll contour optimization.

\section{Conclusions}

(1) For the roll flattening, the change from the roll central to the edge can be regarded as a transformation from plane strain problem to plane stress problem. According to the elastic theory, the calculation formulas are deduced respectively under the assumptions of plane strain and plane stress.

(2) Through introducing the transition coefficient, the plane strain assumption and the plane stress assumption are combined. By using the FEM software, it can be seen that the different rolling force, different flattening width and different roll length have little influence on transition coefficient in a certain range, which can be ignored; while the different roll diameters influence transition coefficient obviously.

(3) Regarding the ratio of the length to roll end and the roll diameter as variable to fit the transition coefficient, the new model of roll flattening is established based on the elastic half plane theory.

(4) By contrast, the modified flattening model has little influence on the distribution of strip thickness and tension, but the influence of pressure distribution between rolls should not be ignored which is of important guiding significance to analyze the roll wear, and so on.

\section{Authors' contributions}

Q-XH was in charge of the whole trial; TW wrote the manuscript; HX and X-DQ assisted with sampling and laboratory analyses. All authors read and approved the final manuscript.

\section{Author details}

${ }^{1}$ College of Mechanical Engineering, Taiyuan University of Technology, Taiyuan 030024, China. ${ }^{2}$ National Engineering Research Center of Cold Strip Rolling Equipment and Technology, Yanshan University, Qinhuangdao 066004, China.

\section{Authors' Information}

Tao Wang, born in 1985, is currently a lecturer at Taiyuan University of Technology, China. He received his Ph.D. degree from Yanshan University, China, in 2013. His research interests include rolling process and equipment.

Qing-Xue Huang, born in 1960, is currently a professor at Taiyuan University of Technology, China. He received his PhD degree from Yanshan University, China, in 1999. His research interests include rolling process and equipment, composite material forming and mechanical design. 
Hong Xiao, born in 1962, is currently a professor at Yanshan University, China. He received his Ph.D. degree from Yanshan University, China, in 1991. His research interests include computer simulation of rolling process and plastic processing theory.

Xiang-Dong Qi, born in 1970, is currently a professor at Yanshan University, China. He received his Ph.D. degree from Yanshan University, China, in 2002. His research interests include shape control theory, rolling process and equipment.

\section{Competing interests}

The authors declare that they have no competing interests.

\section{Funding}

Supported by Shanxi Provincial Science and Technology Major Project of China (Grant No. MC2016-01), Major Program of National Natural Science Foundation of China (Grant No. U1710254), and Natural Science Foundation of Shanxi Province (Grant No. 201701D221143).

\section{Publisher's Note}

Springer Nature remains neutral with regard to jurisdictional claims in published maps and institutional affiliations.

Received: 10 April 2017 Accepted: 30 May 2018

Published online: 19 June 2018

\section{References}

[1] Z C Lin, V H Lin. A study of radial thermal expansion of a work roll for three-dimensional strip deformation during rolling. Journal of Materials Processing Technology, 1997, 70(1-3): 62-76.

[2] V Salganik. Mathematical modelling of roll load and deformation in a four-high strip mill. Journal of Materials Processing Technology, 2002, 125(02): 695-699.

[3] R Nandan, R Rai, R Jayakanth, et al. Regulating crown and flatness during hot rolling: a multiobjective optimization study using genetic algorithms. Advanced Materials and Manufacturing Processes, 2005, 20(3): 459-478.

[4] Y S Hu, X R Cheng, HX Li, et al. Roll deformation rule of varying contact length back-up roll under the condition of equal contact pressure between rolls. Research on Iron \& Steel, 2006, 34(3): 37-39. (in Chinese)

[5] D H Zhang, J Z Cao, J J Xu, et al. Simplified weighted velocity field for prediction of hot strip rolling force by taking into account flattening of rolls. Journal of Iron and Steel Research, International, 2014, 21(7): 637-643.

[6] R Li, Q Zhang, X Zhang, et al. Control method for steel strip roughness in two-stand temper mill rolling. Chinese Journal of Mechanical Engineering, 2015, 28(3): 573-579.

[7] J Cao, X Chai, Y Li, et al. Integrated design of roll contours for strip edge drop and crown control in tandem cold rolling mills. Journal of Materials Processing Technology, 2017, 252(7): 432-439.

[8] H Liu, S Chen, Y Peng, et al. Strip layer method for analysis of the threedimensional stresses and spread of large cylindrical shell rolling. Chinese Journal of Mechanical Engineering, 2015, 28(3): 556-564.

[9] Y Zhao, C Xia, H Wang, et al. Analysis and numerical simulation of rolling contact between sphere and cone. Chinese Journal of Mechanical Engineering, 2015, 28(3): 521-529.

[10] D Wang, H Liu, Liu J. Research and development trend of shape control for cold rolling strip. Chinese Journal of Mechanical Engineering, 2017, 30(5): 1248-1261.

[11] Y Tozawa, M Ueda. Analysis to obtain the pressure and distribution from the contour of deformed roll. Journal of the Japan Society for Technology of Plasticity, 1970, 11: 29-37.
[12] M C Chen, H Q Yu. Three-dimensional surface crack analysis of elastic halfspace under rolling contact load. International Journal of Computational Methods, 2011, 06(2): 317-332.

[13] R J Roark. Formulas for stress and strain. New York: McGraw-Hill, 1954.

[14] B Berger, O Pawelski, P Funke. Elastic deformation of rolls in four-high rolling stands. Archiv fuer das Eisenhuettenwesen, 1976, 47(6): 351-356.

[15] A Hacquin, P Montmitonnet, J P Guillerault. A three-dimensional semianalytical model of rolling stand deformation with finite element validation. European Journal of Mechanics - A/Solids, 1998, 17(1): 79-106.

[16] H L Yu, X H Liu, GT Lee. Contact element method with two relative coordinations and its application of prediction for strip profile for a sendzimir mill. ISIJ International, 2007, 47(7): 996-1005.

[17] H L Yu, X H Liu, GT Lee, et al. Numerical analysis of roll deflection for sendzimir mill. Journal of Manufacturing Science and Engineering, 2008 130(1): 0110161-0110167.

[18] H L Yu, X H Liu, G T Lee, et al. Numerical analysis of strip edge drop for sendzimir mill. Journal of Materials Processing Technology, 2008, 208: 42-52.

[19] ZY Jiang, A K Tieu. Contact mechanics and work roll wear in cold rolling of thin strip. Wear, 2007, 263(7-12): 1447-1453.

[20] ZY Jiang, D Wei, A KTieu. Analysis of cold rolling of ultra thin strip. Journal of Materials Processing Technology, 2009, 209(9): 4584-4589.

[21] S Zhou, P Funke, J Zhong. Influence of roll geometry and strip width on flattening in flat rolling. Steel Research International, 1996, 67(5): 200-204.

[22] S Zhou, P Funke, J Zhong, et al. Modification of a classical formula for determination of roll flattening in flat rolling. Steel Research International, 1996, 67(11): 491-494.

[23] H Xiao, Z W Yuan, TWang. Roll flattening analytical model in flat rolling by boundary integral equation method. Journal of Iron and Steel Research, International, 2013, 20(10): 39-45.

[24] ZW Yuan, H Xiao. Plate shape control theory and experiment for 20-high mill. Journal of Iron and Steel Research, International, 2015, 22(11): 996-1001.

[25] ZW Yuan, H Xiao, H B Xie. Practice of improving roll deformation theory in strip rolling process based on boundary integral equation method. Metallurgical and Materials Transactions A, 2014, 45(2): 1019-1026.

[26] ZW Yuan, H Xiao, H B Xie. 6-Hi mill deformation analysis based on boundary integral equation method. Journal of Mechanical Engineering, 2013, 49(18): 125-131. (in Chinese)

[27] Z K Ren, ZW Yuan, H Xiao, et al. Plate shape control of work roll edge contact for 4-Hi mill. Journal of Yanshan University, 2016, 40(1): 39-44. (in (hinese)

[28] Q L Wang, J Sun, Y M Liu, et al. Analysis of symmetrical flatness actuator efficiencies for UCM cold rolling mill by 3D elastic-plastic FEM. The International Journal of Advanced Manufacturing Technology, 2017, 92(1-4): 1371-1389.

[29] F S Du, T Xue, J N Sun. FEM analysis for roll deformation and flattening of six-high CVC mill. Journal of Yanshan University, 2011, 35(5): 396-401. (in Chinese)

[30] J N Sun, T Xue, F S Du. FEM Analysis of contact stress and crown control for six-high CVC mill. Iron \& Steel, 2012, 47(2): 49-52. (in Chinese)

[31] K Z Linghu, ZY Jiang, J W Zhao, et al. 3D FEM analysis of strip shape during multi-pass rolling in a 6-high CVC cold rolling mill. The International Journal of Advanced Manufacturing Technology, 2014, 74(9-12): 1733-1745.

[32] M A Cavaliere, M B Goldschmit, E N Dvorkin. Finite element simulation of the steel plates hot rolling process. International Journal for Numerical Methods in Engineering, 2001, 52(52): 1411-1430.

[33] STimoshenko. Theory of elasticity. New York: McGraw-Hill, 1951.

[34] TWang, H Xiao, TY Zhao, et al. Improvement of 3-D FEM coupled model on strip crown and flatness in hot rolling. Journal of Iron and Steel Research, International, 2012, 19(3): 14-19. 